\title{
A Metodologia ativa de instrução pelos colegas associada à videoanálise de experimentos de cinemática como introdução ao ensino de funções
}

The Active methodology of peer instruction associated with videoanalysis of kinematics experiences as an introduction to teaching function

\author{
Cláudia Brasil Coimbra Nascimento ${ }^{1}$, Alexandre Lopes de Oliveira*2@ \\ ${ }^{1}$ Instituto Federal de Educação Ciência e Tecnologia do Rio de Janeiro, Rio de Janeiro, RJ, Brasil. \\ ${ }^{2}$ Fundação de Apoio à Escola Técnica, Rio de Janeiro, RJ, Brasil.
}

Recebido em 3 de julho de 2019. Revisado em 24 de janeiro de 2020. Aceito em 30 de janeiro de 2020.

\begin{abstract}
Como resultado de estudos para aplicações interdisciplinares desenvolvidos em curso de Mestrado em Ensino de Ciências, com o intuito de orientar professores e graduandos de licenciatura das áreas de Física, Matemática e afins para práticas inovadoras junto ao corpo discente, o presente estudo trata do ensino de funções em turmas de $9^{\circ}$ ano do Ensino Fundamental, envolvendo a Matemática e a Física, a partir do delineamento quase-experimental de série temporal. Por meio da videoanálise de pequenos experimentos de cinemática realizados pelos alunos, com a utilização do software livre Tracker, foram tratadas questões acerca de funções afins e quadráticas, derivadas dessas experiências e observações, com pré-testes e pós-testes conceituais ao longo de seis aulas duplas, intercalando a realização dos experimentos físicos e a aplicação dos testes. A videoanálise dos experimentos de cinemática, com conclusões alcançadas pelos alunos, entrou como fator introdutório e embasador do tema funções. Os pré e pós-testes foram mediados pela metodologia ativa de Instrução pelos Colegas - IpC e a troca de entendimentos e experiências entre os grupos participantes possibilitou a avaliação e medição do estudo quanto à sua eficácia. O tratamento foi aplicado em três turmas de uma escola da Fundação de apoio à Escola Técnica do Rio de Janeiro, totalizando a participação de 76 alunos. Os resultados desta pesquisa, obtidos no desenvolvimento das atividades, estudados pela análise estatística do ganho normalizado de Hake sob o delineamento quase-experimental, indicam a possibilidade de se utilizar a metodologia ativa proposta como potencial mediadora da relação ensino-aprendizagem em contextos colaborativos.
\end{abstract}

Palavras-chave: videoanálise, cinemática, funções, quase-experimental, instrução pelos colegas.

As a result of studies for interdisciplinary applications developed under a Master's Degree in Science Teaching, with the aim of orienting teachers and undergraduate students in Physics, Mathematics and related fields for innovative practices next to the student body, this study deals with the teaching of functions in classes of 9th grade of Elementary School, involving Mathematics and Physics, from the quasi-experimental delimitation of time series. By means of the videoanalysis of small kinematics experiments carried out by the students, using the free software Tracker, questions were treated about related and quadratic functions, derived from these experiments and observations, with pre-tests and conceptual tests of six double classes, intercalating the accomplishment of the physical experiments and the application of the tests. The videoanalysis of the kinematics experiments, with conclusions reached by the students, entered as an introductory factor and basis of the functions theme. The pre and post-tests were mediated by the active methodology of Peer Instruction and the exchange of understandings and experiences between the participating groups made possible the evaluation and measurement of the study regarding its effectiveness. The treatment was applied in three classes of a school of the Foundation of support to the Technical School of Rio de Janeiro, totalizing the participation of 76 students. The results of this research, obtained in the development of the activities, studied by the statistical analysis of Hake's normalized gain under the quasi-experimental design, indicate the possibility of using the proposed active methodology as potential mediator of the teaching-learning relationship in collaborative contexts

Keywords: videoanalysis, kinematics, functions, quasi-experimental, peer instruction.

\section{Introdução}

O presente estudo envolve a realização em sala de aula de experimentos físicos simples de cinemática, promovidos

*Endereço de correspondência: alexandre.oliveira@ifrj.edu.br pelo corpo discente participante, vinculados à construção 
de conceitos de funções afins e quadráticas. A partir da videoanálise dos pequenos experimentos de cinemática realizados, pelo uso do software livre Tracker, o aluno é convidado a construir, de forma diferenciada, o estudo dos conceitos de funções, mediado pelo uso da metodologia ativa Peer Instruction, tratada neste estudo na sua tradução Instrução pelos Colegas (IpC), com questões conceituais embasadas nos experimentos físicos. A metodologia proposta, sob à investigação quase-experimental para o ensino das funções, traz a oportunidade de dinamizar a abordagem, promover maior interação e auxílio para entendimentos e discussão entre colegas, uma vez que busca contextualização, experimentação, interdisciplinaridade e uso da tecnologia por meio do software de videoanálise, trazendo a possibilidade de respostas em tempo real, a fim de facilitar a avaliação do docente quanto à eficácia da proposta.

A pesquisa tem por objetivo geral investigar como a Metodologia Ativa IpC, associada à videoanálise de experimentos de cinemática, pode contribuir para aprendizagem do corpo discente acerca de funções. Associando questões do cotidiano por meio da experimentação, além de construir o conceito de funções, a pesquisa também visa levar o aluno a identificar a lei de formação das funções abordadas, analisar gráficos estabelecidos em função dos dados observados nos experimentos, associando elementos pertinentes aos conceitos.

Segundo as políticas do Ministério de Educação, encontram se as coleções de livros aprovados para os anos finais do Ensino Fundamental, incluindo-se os conteúdos de equações e funções distribuídas ao longo do $7^{\circ}, 8^{\circ}$ e $9^{\circ}$ ano [1], sendo nesse último enfocadas as funções lineares e quadráticas e, para o Ensino Médio, o ensino mais aprofundado desse conteúdo [2].

Ao longo dos anos, o conceito de função passou por um processo de construção, evolução e refinamento chegando até às notações e representações gráficas de hoje. Para a BNCC, o ensino das funções para o $9^{\circ}$ ano do Ensino Fundamental sugere a forma de como se construir esses conteúdos é que pode fazer toda a diferença, para atender ao objetivo de "compreender as funções como relações de dependência unívoca entre duas variáveis e suas representações numérica, algébrica e gráfica e utilizar esse conceito para analisar situações que envolvam relações funcionais entre duas variáveis." [3].

\section{O Delineamento Quase-experimental}

Estudos quase-experimentais caracterizam-se por não necessitarem de longos períodos de observação e coleta de dados. A validade interna desse tipo de estudo baseiase na escolha da amostra ou grupo de incidência não aleatório. Não têm por objetivo fazer generalizações e têm por base a testagem de hipótese para eliminação de variáveis a fim de levantar questões pertinentes que permitam estudos futuros mais profundos e que favoreçam uma futura argumentação teórica. Flexibilizam condi- ções impostas por modelos de investigação experimental puros. A comparação entre as condições de tratamento e não-tratamento deve sempre ser feita com grupos não equivalentes ou com os mesmos sujeitos antes do tratamento.

De acordo com Campbell e Stanley [4], os métodos quase-experimentais constituem uma classe de estudos de natureza empírica onde faltam duas características usuais na experimentação: um controle completo e a aleatoriedade na seleção de grupos. Pesquisas quase-experimentais podem ser realizadas com a análise comparativa entre grupos de controle e grupos experimentais (GC e GE), com séries cronológicas ou temporais pela aplicação de diversos pré e pós-testes a um mesmo grupo, ou, ainda, por meio de análise de variáveis após o fato ocorrido ("ex post facto"). Delineamentos de séries temporais são extensões do delineamento pré-experimental de pré e pós-teste com um determinado grupo.

As razões para a realização de um estudo quaseexperimental decorrem da natureza da variável independente ou do perfil dos sujeitos. Delineamentos experimentais clássicos consistem em distribuir aleatoriamente pelas condições da variável independente e em medir uma variável dependente, mantendo as demais variáveis constantes, proporcionando-lhes alta validade interna. Os delineamentos quase-experimentais surgem da necessidade de realizar pesquisas aplicadas, em situações em -que não é possível atingir o mesmo grau de controle que nos delineamentos experimentais propriamente ditos, onde tentam atingir um grau próximo à experimentos puros, para inferir que dado tratamento tenha o efeito pretendido [5].

Em quase-experimentos, o grupo controle é comumente chamado grupo de comparação, visto que não atende aos requisitos de aleatorização e pode não ser completamente equivalente ao grupo experimento. $\mathrm{O}$ desenho de série de temporal envolve um único grupo. Nesse caso, o fenômeno de interesse é medido ao longo do tempo e em algum momento é inserida a intervenção. $\mathrm{O}$ uso de um período amplo para coleta de dados visa minimizar ameaças à validade dos dados e efeitos de história (tendência temporal).

A análise estatística em estudos experimentais e quaseexperimentais pode ser realizada entre os participantes que foram submetidos à intervenção até o final do estudo ou entre todos os participantes, independente de terem ou não participado até o final (no caso de GE e GC), e a amostra selecionada deve ter tamanho suficiente para obter significância estatística em relação ao efeito da intervenção. Num experimento a variável a ser manipulada é sempre a variável independente.

No presente estudo, todos os alunos participantes receberam o mesmo tratamento de série temporal, por um período de seis aulas duplas, intercalando experimentos, videoanálise e testes conceituais. A evolução da aplicação foi tratada pela resposta dos alunos no decorrer do tratamento. A variável independente (causa) está 
nos movimentos dos pequenos objetos nas experimentações realizadas pelo corpo discente e o efeito construção do conceito de funções "depende" dessas experimentações e para medir os efeitos das variáveis investigadas, utilizando-se pré-testes conceituais e pós-testes, mediante a necessidade do grupo (intervenção), por meio da metodologia ativa IpC.

\section{A metodologia ativa de Instrução pelos Colegas e o instrumento de videoanálise}

A metodologia ativa Peer Instruction, numa tradução livre, "instrução entre pares" ou "instrução pelos colegas" (IpC), foi proposta pelo Professor de Física da Universidade de Harvard Eric Mazur durante os anos 1990. Prima pelo entendimento e aplicabilidade dos conceitos, utilizando-se da discussão entre os alunos. Surgiu da necessidade, percebida por Mazur, de melhor compreensão dos conceitos básicos da Física, uma vez que não estavam sendo devidamente assimilados pelos estudantes. Ele defende que o entendimento e apreensão conceitual é o primeiro passo da aquisição do conhecimento de determinada área. Se os alunos têm domínio conceitual, é preciso desenvolver suas habilidades em aplicá-lo nas situações práticas - que é, na realidade, o esperado do profissional em sua atuação [6]. Pela metodologia desenvolvida, exige-se que os alunos leiam, pensem e reflitam antes da aula.

Consiste uma breve apresentação do tema, problematizando e fazendo a pergunta que irá nortear o debate entre os estudantes. Em seguida, provocada a discussão entre pares de alunos, esses utilizam um aparelho conhecido como clicker, após a discussão, para responder individualmente à pergunta do professor. As respostas são transmitidas para o computador do professor e projetadas de modo que todos possam ver. O tema é retomado e problematizado, encorajando a discussão sobre as diferentes respostas, onde o professor circula pela sala de aula e conversa com os alunos, com o apoio de monitores. Ele novamente provoca a discussão entre os pares para que os alunos discutam as respostas do primeiro debate e as referências do professor. Novamente solicita que os alunos utilizem os clickers e respondam à questão inicial. Após essa última resposta, discute-se com os alunos o resultado final apontando a solução do problema. Respondidas essas questões iniciais e a partir da análise de tais resultados, a aula pode tomar rumos diferentes, conforme o percentual individual de erros/acertos.

Uma das principais ideias do método é fazer com que os alunos interajam entre si ao longo das aulas, procurando explicar, uns aos outros, os conceitos que estão sendo abordados, por meio de questionamentos estruturados, que serão apresentados pelo professor (essas questões conceituais foram definidas pelo autor como testes conceituais - ConcepTests). Este método auxilia para que os alunos se envolvam com o conteúdo de ensino, pro- movendo o aprendizado colaborativo. Pressupõe que o professor limite a exposição inicial de um conceito em um curto intervalo de tempo, quando então apresenta um teste conceitual de múltipla escolha, a ser respondido individualmente pelos alunos (entre 2 a 4 minutos) [7]. Dependendo do índice de acertos da turma, o professor deve refazer a exposição, quando o índice de acertos for abaixo dos $30 \%$, formar duplas ou pequenos grupos de alunos, que são estimulados a debaterem e chegarem a um consenso quanto a resposta ao teste, quando o índice de acertos estiver entre $30 \%$ e $70 \%$, ou seguir em frente para o próximo teste conceitual, quando o índice de acertos for superior a 70\%, após uma breve explicação da resposta, sem a necessidade de aprofundamento. Quando o índice de acertos for inferior a 30\%, o professor, após explicar novamente o assunto abordado, deve posteriormente apresentar novamente um teste similar sobre o assunto ou o mesmo teste, reiniciando o ciclo. Cabe esclarecer que, quando o índice de acertos ficar entre $30 \%$ e $70 \%$, após o debate entre duplas ou grupos sugerido pelo professor, cada aluno apresenta a sua resposta individualmente. O intervalo de acertos entre $30 \%$ e $70 \%$ não é universal, cabendo ao professor reajustar segundo suas necessidades. A breve exposição deve durar de 10 a 15 minutos, enfatizando conceitos ideias que fundamentam o princípio, evitando equações e deduções matemáticas.

A Figura 1 retrata o fluxograma implementado por Mazur.

As respostas podem ser informadas ao professor de diversas maneiras, entre elas encontram-se: levantar a mão (o professor pode pedir para cada estudante levantar a mão para escolher sua resposta); flashcards, onde cada estudante recebe um conjunto de cartões (contendo as alternativas A, B, C, D, E) para sinalizar a resposta a uma questão; clickers, dispositivo remoto de resposta utilizado por Mazur; plickers (https://plickers.com), que é um software que pode ser baixado gratuitamente pelas lojas oficiais do Android (Playstore) e Apple (apple store) e reproduz o funcionamento dos clickers. O professor, com um celular que contenha o aplicativo Plickers, conse-

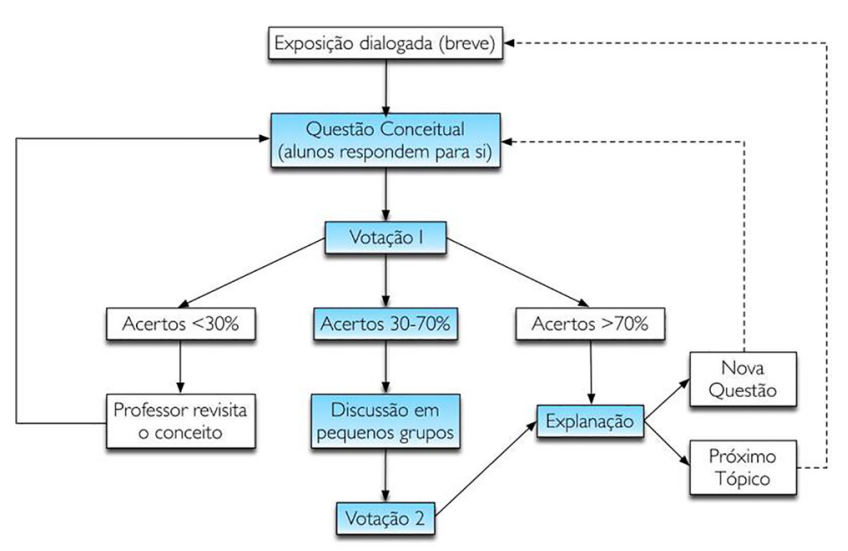

Figura 1: Diagrama do processo de implementação do método IpC (ARAUJO e MAZUR, 2013) 
gue escanear as respostas e, após o registro, o aplicativo fornece uma parcial daquela questão com relação àquela turma. Este último foi o método de captura de respostas escolhido para a presente pesquisa.

Os resultados do método IpC são monitorados pelo computador ou pelo aplicativo de celular. A Figura 2 (a) demonstra a utilização do aplicativo, apresentando um teste conceitual em ela a ser aplicado na turma. Já a Figura 2 (b) demonstra o scanner em funcionamento durante a realização de uma das aulas da sequência didática da presente pesquisa.

A resposta em tempo real é informada no próprio aplicativo. Durante a captura do scanner, as respostas certas aparecem em verde na imagem e as erradas em vermelho. Os gráficos comparativos de cada teste conceitual ficam armazenados no site do aplicativo e podem ser consultados imediatamente após a aplicação por meio do celular utilizado como scanner ou a qualquer tempo.

De acordo com Araújo e Mazur [8], para que um teste conceitual seja efetivo, as questões devem requerer reflexões sobre os conceitos de modo que os estudantes não consigam respondê-las meramente substituindo valores em fórmulas, ou simplesmente usando a memória sobre algo que foi discutido anteriormente. Os testes conceituais utilizados na presente pesquisa foram construídos de forma a investigar o entendimento dos alunos participantes a cerca da videoanálise de experimentos, evoluindo para a construção da lei de formação de funções afins e quadráticas associadas a essas videoanálises, além de conceitos correlatos como a construção dos gráficos associados, coeficientes constantes na lei de formação de cada função, entre outros, sempre buscando uma definição conceitual, evitando cálculos de equações extensas ou questões que exigissem um tempo maior de resolução que não se enquadrasse nos moldes da aplicação da metodologia IpC. São testes originais, por estarem associados aos experimentos realizados pelo corpo discente e por não foar em resolução de exercícios numéricos, diferente do foco de livros didáticos voltados para a Matemática de Ensino Fundamental.

A videoanálise de experimentos, realizados pelo corpo discente participante, entra como instrumento introdu-
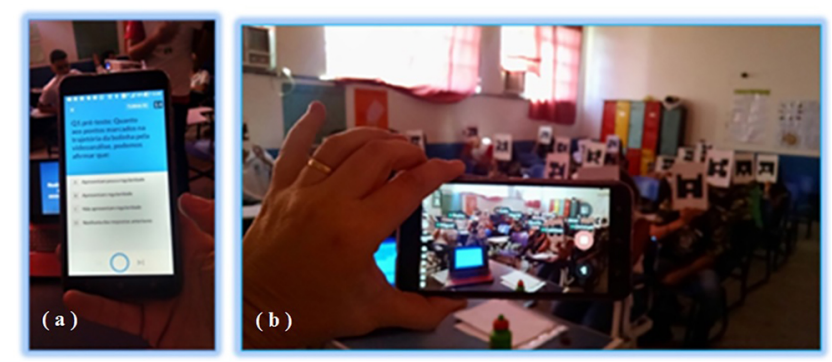

Figura 2: (a) Dispositivo Plickers preparado para captura de respostas em um teste conceitual; (b) Docente utilizando o scanner por meio do aplicativo para capturar as respostas dos alunos. Fonte: Acervo pessoal tório para o trato da metodologia ativa, embasando, em aula posterior, os testes conceituais do IpC. É um instrumento tratado pelo software livre Tracker, gratuito para download, que oferece ferramentas para a análise de vídeos (http://physlets.org/tracker) e destina-se à análise quadro a quadro de vídeos (videoanálise), permitindo o estudo de diversos tipos de movimento a partir de filmes produzidos por câmaras digitais ou webcams [9]. Foi desenvolvido por Douglas Brown, Doutor em física pela Universidade do Colorado, professor do Cabrillo College entre 1977 e 2008, em parceria com o Open Source Physics (OSP). Permite um tratamento científico dos arquivos em formato vídeo, obtendo estimativas para parâmetros diversos, evolução temporal de grandezas, entre outras aplicações $[9,10,11]$. A plataforma Java é necessária como linguagem de programação para a utilização do software livre Tracker. A Figura 3 ilustra a interface gráfica do software.

A filmagem a ser tratada pelo software Tracker passa por ajustes antes da análise, como a delimitação do tempo de percurso a ser analisado, a criação de um referencial de escala associada ao experimento real, o ponto de massa, a marcação do eixo cartesiano, a marcação de todo o percurso delimitado a partir do deslocamento desse ponto de massa (deslocamento do objeto na filmagem). A partir disso, é possível avaliar os movimentos capturados por meio do programa e levantar questionamentos junto aos alunos sobre o que acontece com os pontos da trajetória capturada, como a apresentação do gráfico, se há proporcionalidade nos movimentos, entre outros. Decorrente das análises em função da experimentação, os alunos têm a oportunidade de associar o conceito e a construção da função a ser descoberta e fornecida por meio do software em relação aos movimentos capturados e concluir as associações necessárias.

É importante que exista um fundo estacionário, permitindo embasamento para a investigação. Pode-se fixar uma régua ao plano de fundo ou um outro objeto fixo que se conheça a medida, por exemplo, para servir de escala para o trato da videoanálise. No presente estudo, foi utilizada uma prancha com fundo centimetrado para facilitar o uso do software.

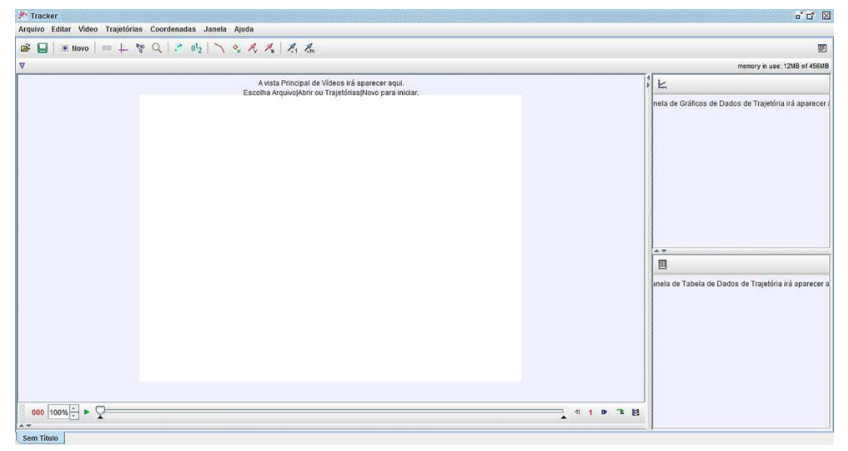

Figura 3: Interface gráfica do programa Tracker. Versão em português 


\section{A Metodologia}

O estudo foi realizado em três turmas de $9^{\circ}$ ano de educação básica de uma escola pertencente à Fundação de apoio à Escola Técnica do Rio de Janeiro. Ao todo foram 76 alunos participantes, sendo 27 alunos participantes na turma 1, 24 alunos na turma 2 e 25 alunos na 3 . A sequência didática foi realizada em 6 aulas duplas que aconteceram nos mesmos dias letivos nas três turmas participantes, no terceiro trimestre do ano letivo de 2018. A sequência de 6 aulas duplas contou como uma aula introdutória, para familiarização e conhecimento da metodologia IpC e do software Tracker, seguida de aulas de experimentos de cinemática e posterior videoanálise, intercaladas com aulas de aplicação da metodologia IpC.

Dos acessórios utilizados para o desenvolvimento do projeto de pesquisa, destacamos um laptop, um tripé, um projetor Datashow e três smartphones. Um dos smartphones tinha conexão com a internet e destinava-se à captura dos dados por meio das votações pelo aplicativo plickers.com. O outro smartphone foi utilizado pelo corpo discente para a captura dos movimentos por eles experimentados nas aulas destinadas à videoanálise. O terceiro smartphone teve função para fotos promovidas pelos alunos dos eventos ocorridos.

Além desse material, foram utilizados pequenos objetos para promover as experimentações e posterior videoanálises, São eles: bola de mouse, bola de borracha, carrinho de fricção, carrinho de ferro, carrinho com lançador, peças de dominó, raquetes e bola de ping pong, biboquê, aparelho para drenagem de líquido. Também os cartões individuais e numerados para uso dos alunos nas votações da metodologia IpC. Os materiais para movimentação e realização de experimentos e os smartphones para captura de movimentos para estudo em videoanálise e para fotografar as cenas dos eventos ocorridos foram utilizados exclusivamente pelo corpo discente participante, sob orientação da docente.

O Quadro 1 demonstra a sequência didática com a discriminação de datas, horários e especificidades de cada aula dupla.

O tratamento de série temporal de seis aulas duplas envolveu 44 testes conceituais, distribuídos entre pré e pós aplicações, de acordo com a necessidade. Os testes conceituais foram formulados e selecionados de acordo com critérios estabelecidos na literatura internacional, ou seja, testes conceituais de múltipla escolha e abordando conceitos que exigem raciocínio dos alunos para o entendimento do conteúdo, ao invés de forçá-lo a memorizar fórmulas e conceitos, ou que simplesmente substitua um número em uma fórmula [7]. Esses testes foram embasados nos experimentos de cinemática realizados pelos alunos e tratados em videoanálise, trazendo significado ao debate e consequente resposta aos questionamentos. Os testes conceituais formulados a partir do tratamento em videoanálise dos experimentos físicos foram criados de modo que cada questão tratasse de uma experimentação analisada.

A primeira aula de experimentação foi destinada ao alcance da lei de formação de funções afins a partir de experiências realizadas pelos próprios alunos. A primeira turma a receber o tratamento, de acordo com o horário oficial da escola, foi a turma 2. Foram realizados 6 experimentos, respectivamente, rolagem da bola de mouse, da bola de borracha, lançamento do carrinho de fricção, do carrinho com lançador, queda de peças de dominó e queda da água no tubo de drenagem. Cada um desses movimentos contou com a participação de três alunos, sendo um para promover o movimento, outro posicionado para a filmagem do evento e o terceiro aluno responsável por fotografar a cena. Todo evento foi supervisionado pela docente, com orientações sobre o lançamento correto, posicionamento da câmera de filmagem do movimento de forma que a tela permanecesse vertical e o mais imóvel o quanto possível para posterior videoanálise. Dos 6 eventos promovidos, cada um deles contou com a participação de um trio diferente de forma a diversificar a participação e envolver o maior número de alunos das turmas participantes. Independente disso, toda a turma acompanhou cada um dos passos de cada evento, demonstrando interesse e curiosidade. As turmas seguintes, 3 e 1, receberam tratamento análogo. As Figuras 4(a), $4(\mathrm{~b}), 4(\mathrm{c})$ e $4(\mathrm{~d})$ apresentam o preparo de alguns desses movimentos.

É importante salientar que a dificuldade de correlação do experimento físico com a construção de funções e de

\begin{tabular}{|c|c|c|c|c|}
\hline DATAS & \multicolumn{2}{|c|}{$\begin{array}{l}\text { CARGA HO- } \\
\text { RÁRIA }\end{array}$} & $\begin{array}{l}\text { TURMAS PAR- } \\
\text { TICIPANTES }\end{array}$ & PRÁTICA DESENVOLVIDA \\
\hline $10 / 10 / 2018$ & \multirow{3}{*}{ 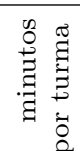 } & \multirow{2}{*}{ ö } & & Introdução ao método IpC com testes conceituais de conteúdos prévios \\
\hline $17 / 10 / 2018$ & & & & $\begin{array}{l}\text { Realização de experimentos e videoanálise associada à função afim pelo } \\
\text { corpo discente }\end{array}$ \\
\hline $22 / 10 / 2018$ & & $\stackrel{\stackrel{+}{0}}{\sigma} \underset{\sigma}{\sigma}$ & & $\begin{array}{l}\text { Aplicação da metodologia ativa IpC associada às videoanálises vinculadas } \\
\text { às funções afins }\end{array}$ \\
\hline $29 / 10 / 2018$ & 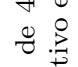 & 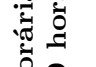 & $\stackrel{0}{\sim}$ & $\begin{array}{l}\text { Realização de experimentos e videoanálise associada à função quadrática } \\
\text { pelo corpo discente }\end{array}$ \\
\hline $05 / 11 / 2018$ & 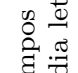 & 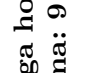 & $\underset{-1}{\tilde{\sigma}}$ & $\begin{array}{l}\text { Aplicação da metodologia ativa IpC associada às videoanálises vinculadas } \\
\text { às funções quadráticas }\end{array}$ \\
\hline $12 / 11 / 2018$ & 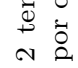 & $\bigcup^{\overparen{Z}}$ & $\underset{\Xi}{\Xi}$ & $\begin{array}{l}\text { Conclusão da sequência didática com da metodologia ativa IpC envolvendo } \\
\text { funções afins e quadráticas }\end{array}$ \\
\hline
\end{tabular}




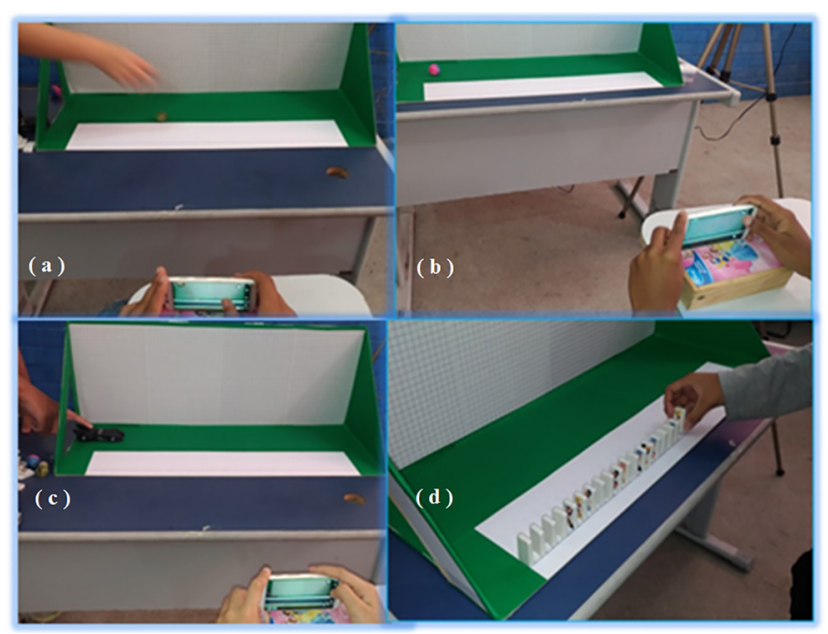

Figura 4: (a) Preparo para movimento da bola de mouse; (b) Preparo para movimento da bola borracha; (c) Preparo para movimento do carrinho friç̧ão; (d) Preparo para movimento de peças dominó Fonte: Acervo pessoal

abstrair o conceito é possivelmente minimizada com esta proposta de abordagem. Para o aluno, principalmente ao final do Ensino Fundamental, a realização dos experimentos foi crucial para a sua concentração e associações pertinentes. Usualmente, ao se apresentar o ensino de funções meramente ilustrativo por meio de livro didático, a dificuldade de abstração e correlação é notória. O vínculo com a cinemática, embasando a abordagem introdutória do tema, permite a interação do aluno e debate de possíveis dificuldades. Os experimentos foram realizados por cada trio de alunos de forma voluntária, onde escolhiam, inclusive, o objeto que desejavam movimentar e filmar. A liberdade de atuação propiciou que, mesmo os alunos mais inibidos, se envolvessem nas construções.

Encerrada a etapa de realização e filmagem dos eventos, a turma foi convidada a manusear o software Tracker. Com o apoio do Datashow, a docente apresentou novamente orientações básicas para o uso do software, reforçando os debates da aula de introdução. A partir de então, alunos participantes foram convidados a utilizar o Tracker para a realização da videoanálise dos experimentos realizados e filmados por eles. Associações da construção de funções afins aos movimentos retilíneo uniforme (MRU) promovidos nos experimentos, foram sinalizados e debatidos junto aos alunos. Dos seis eventos realizados, foram escolhidos dois em cada turma, a critério do aluno voluntário, para tratamento em videoanálise. A Figura 5 demonstra um desses alunos promovendo a videoanálise de experimento escolhido por ele, sob orientação da docente. Todo o tratamento foi acompanhado pela turma participante por meio da imagem projetada no Datashow. As orientações foram realizadas ao longo do processo, bem como questionamentos e dúvidas surgidas foram discutidas e tratadas enquanto um dos alunos promovia o tratamento de videoanálise. Após o tratamento da videoanálise, a docente demonstrou no software

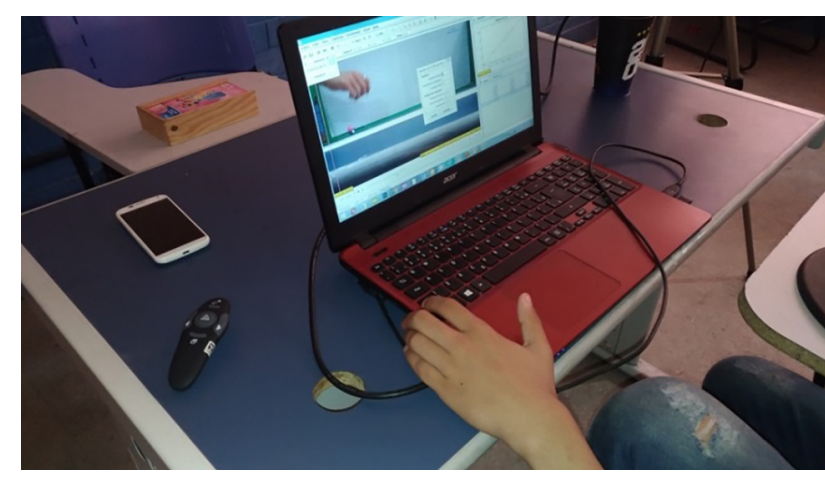

Figura 5: Imagem de videoanálise de movimento de rolagem da bola de borracha, em MRU, realizada por aluna voluntária. Fonte: Acervo pessoal

Tracker e no Excel o acesso à lei de formação das funções afins associadas às videoanálises realizadas. É importante ressaltar a curiosidade das turmas quanto ao software em virtude da correlação com os experimentos físicos.

A dificuldade para lidar com o software ocorreu inicialmente, mas os alunos voluntários para essa tarefa apresentaram bastante interesse e aprenderam o passo a passo orientado pela docente. O tratamento da videoanálise e posterior acesso à lei de formação de cada função obtida em associação aos movimentos realizados, com a cópia de precisão total da tabela de dados do Tracker para o Excel, propiciou o trato de dúvidas quanto aos coeficientes e comportamento de cada função construída.

De forma análoga, a quarta aula dupla da sequência didática foi destinada à realização e filmagem de experimentos de cinemática associados à construção de funções quadráticas.

A segunda aula de experimentação foi destinada ao alcance da lei de formação de funções quadráticas a partir de experiências com movimento de pequenos objetos, realizadas pelos próprios alunos, associadas à construção dessas funções. A primeira turma a receber o tratamento, de acordo com o horário oficial da escola, foi novamente a turma 2. Foram realizados 5 experimentos, respectivamente, lançamento de bola por raquete de jogo de ping-pong, lançamento de bola em biboquê, carrinho de ferro em descida de rampa na prancha de videoanálise, bola de mouse em descida de rampa, lançamento de bola de borracha em queda livre (choque elástico). Cada um desses movimentos contou com a participação de três alunos novamente, sendo um para promover o movimento, outro posicionado para a filmagem do evento e o terceiro aluno responsável por fotografar a cena. Todo evento foi supervisionado pela docente, com orientações sobre o lançamento correto, posicionamento da câmera de filmagem do movimento de forma que a tela permanecesse vertical e o mais imóvel o quanto possível para posterior videoanálise. Dos 5 eventos promovidos, cada um deles contou com a participação de um trio diferente de forma a diversificar a participação e envolver o maior número de alunos das turmas participantes. Por sugestão da do- 
cente, os alunos que não participaram efetivamente da primeira aula de experimentação, foram incentivados a uma participação mais acentuada nessa segunda aula de experimentação. Mesmo àqueles mais tímidos e retraídos foram incentivados à participação. É bem verdade que, mesmo sob insistência, poucos alunos ainda se recusaram à uma participação efetiva das três turmas participantes e, nesse caso, foi respeitado o livre arbítrio dos mesmos. Independente disso, toda a turma acompanhou cada um dos passos de cada evento, sempre demonstrando interesse e acompanhando cada passo dos colegas. As turmas seguintes, 3 e 1, receberam tratamento semelhante. As Figuras $6(\mathrm{a})$ e $6(\mathrm{~b})$ apresentam o preparo de alguns desses movimentos.

O debate, incentivo e auxílio mútuo sempre estiveram presentes. Os alunos que permaneciam na observação também se manifestavam por meio de ideias e orientações aos colegas com participação efetiva, com a preocupação de manterem o celular destinado a filmagem dos eventos sempre imóvel o quanto possível. Também ocorreram algumas tentativas de ensaio e erro, antes das filmagens que puderam ser aproveitadas para videoanálise posterior. Nos eventos de lançamento de bola por raquete de jogo de ping-pong e lançamento de bola em biboquê não foi possível utilizar a prancha de videoanálise. Nesse caso, para bastão de calibração foi utilizada a medida do comprimento do "tijolinho azul" na parede da sala de aula, com $23 \mathrm{~cm}$ de comprimento.

Encerrada a etapa de realização e filmagem dos eventos, a turma foi convidada a utilizar novamente o software Tracker, mas dessa vez para o trato de funções quadráticas. Com o apoio do Datashow, a docente relembrou orientações básicas e, a partir de então, alunos participantes foram convidados a utilizar o Tracker a partir dos experimentos realizados e filmados por eles nessa segunda aula de experimentação. Associações da construção de funções quadráticas aos movimentos uniformemente variados (MUV) promovidos nos experimentos, em virtude da presença de aceleração, foram sinalizados e debatidos junto aos alunos. Dos cinco eventos realizados, foram escolhidos dois em cada turma, a critério do aluno voluntário, para tratamento em videoanálise. A Figura 7 apresenta o print da videoanálise realizada por um desses alunos em experimento escolhido por ele, sob orientação da docente.

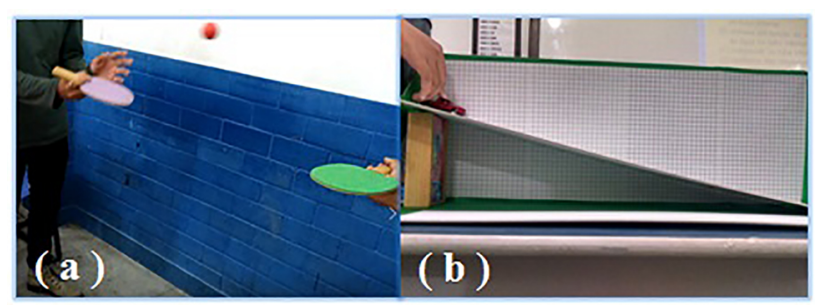

Figura 6: (a) Imagem de movimento de bola de ping-pong; (b) Imagem de movimento de carrinho Fonte: Acervo pessoal

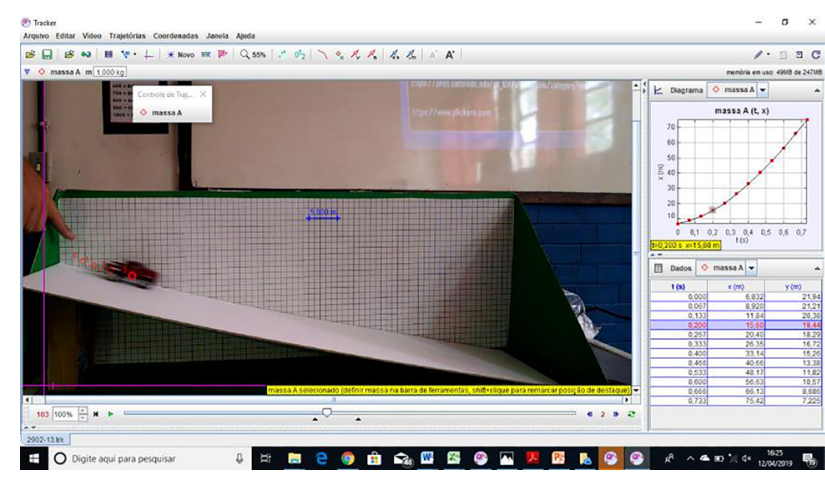

Figura 7: Print de videoanálise do movimento de carrinho descendo rampa, em MUV, realizada por aluno participante, sob orientação da docente. Fonte: Acervo pessoal

Todo o tratamento foi acompanhado pela turma participante por meio da imagem projetada no Datashow. Da mesma forma que na primeira aula de experimentação, as orientações foram sendo realizadas ao longo do processo, bem como questionamentos e dúvidas surgidas foram sendo discutidas e tratadas enquanto um dos alunos promovia o tratamento de videoanálise. Mais uma vez o uso do Tracker permitiu a devida correlação do experimento físico com a construção matemática. Analogamente, a cópia de precisão total da tabela de dados fornecida pelo software em cada experimento tratado foi levada ao Excel para a construção da linha de tendência e da função associada a cada experimento realizado, possibilitando o aprofundamento e debate de dúvidas quanto à lei de formação de cada função abordada ao longo da sequência didática, explicitando coeficientes e comportamento de cada uma.

Após o tratamento da videoanálise, a docente demonstrou no software Tracker e no Excel o acesso à lei de formação das funções quadráticas associadas às videoanálises realizadas. É importante lembrar que, para as aulas de aplicação da metodologia IpC, a docente completou extra classe as videoanálises de todos os experimentos realizados pelos alunos, uma vez que nas aulas de experimentação só houve tempo hábil para o trato de duas videanálises por turma em cada aula dupla de experimentação e, ao todo, foram realizados 6 experimentos associados à função afim e 5 experimentos associados à função quadrática em cada turma. As videoanálises, com respectivas associações no software Excel, de todos os experimentos realizados e filmados pelos alunos embasaram os questionamentos votados por meio dos cartões Plickers na aplicação da metodologia.

\section{Os testes conceituais}

Na primeira aula dupla, destinada à introdução da metodologia, os alunos participaram de votações de testes conceituais envolvendo conteúdos prévios para conhecimento e familiarização com a metodologia IpC. Os cartões fornecidos pelo aplicativo plickers.com foram dis- 
tribuídos pela docente aos alunos, onde cada um tomou posse de uma numeração específica para uso em toda a sequência didática.

Nessa aplicação não foram desenvolvidos pós-testes diferenciados dos pré-testes. Para que o corpo discente conhecesse e desenvolvesse a metodologia, em questões votadas na porcentagem $\mathrm{x}$, com $30 \%<\mathrm{x}<70 \%$, os póstestes foram tratados com as mesmas questões introduzidas em pré-testes, pois o objetivo maior era de aprender a utilizar os cartões e entender a metodologia adotada por toda a sequência didática. Com o apoio do Datashow, a docente apresentou também o software Tracker, fornecendo orientações básicas para o seu uso e, baseando-se em dois eventos filmados e tratados em videoanálise previamente por ela, incluiu algumas questões para votação pelo Plickers associadas aos gráficos apresentados no Tracker envolvendo questões prévias como eixos, quadrantes, pares ordenados e tipo de movimento, além de primeiras impressões sobre o software. A Quadro 2 demonstra algumas das questões abordadas na aula de introdução.

Em virtude da segunda e quarta aula dupla terem sido destinadas à experimentação e videoanálise, a metodologia IpC foi aplicada, além da aula de introdução à metodologia, na terceira e quinta aulas duplas, intercalando com as aulas de experimentação, e na sexta e última aula dupla, como conclusão da sequência didática, envolvendo nessa última questões sobre as duas funções experimentadas (afins e quadráticas).

A terceira aula dupla, segunda aula de aplicação do IpC, foi baseada em 10 questionamentos objetivos associados às videoanálises promovidas com base nas experi- mentações de cinemática em MRU realizadas na segunda aula dupla. Cada questão contou com uma breve explanação com apresentação de videoanálise de algum dos experimentos realizados. Da mesma forma, foram apresentadas as videoanálises e respectivos gráficos em Excel dos experimentos com a bolinha de mouse, carrinho de fricção, carrinho com lançador, queda de peças de dominó e queda d'água no tubo. Foram abordadas questões como proporcionalidade, regularidade, lei de formação de funções afins, coeficientes de funções, funções constante, crescente e decrescente, além do reforço de conceitos na construção de gráficos como eixos, pares ordenados e relação entre coordenadas cartesianas.

A Figura 8(a) apresenta o print da videoanálise do experimento de rolagem da bolinha de borracha na prancha de videoanálise e a Figura 8(b) apresenta o print do gráfico em Excel e respectiva lei de formação da função associada à videoanálise específica, a título de exemplo de desenvolvimento da metodologia, e o Quadro 3 apresenta algumas questões conceituais abordadas nessa aula.

A quinta aula dupla, terceira aula de aplicação do IpC, foi baseada igualmente em 10 questionamentos objetivos associados às videoanálises promovidas com base nas experimentações realizadas na quarta aula da sequência didática e segunda aula destinada à experimentação, contando com breve explanação associada à apresentação de videoanálise de algum dos experimentos realizados na quarta aula dupla. Da mesma forma, foram apresentadas as videoanálises e respectivos gráficos em Excel dos experimentos de cinemática em MUV com o lançamento de bola de ping pong, bola no biboquê, carrinho ou bola

Quadro 2: Algumas questões aplicadas na aula de IpC destinada à introdução do método
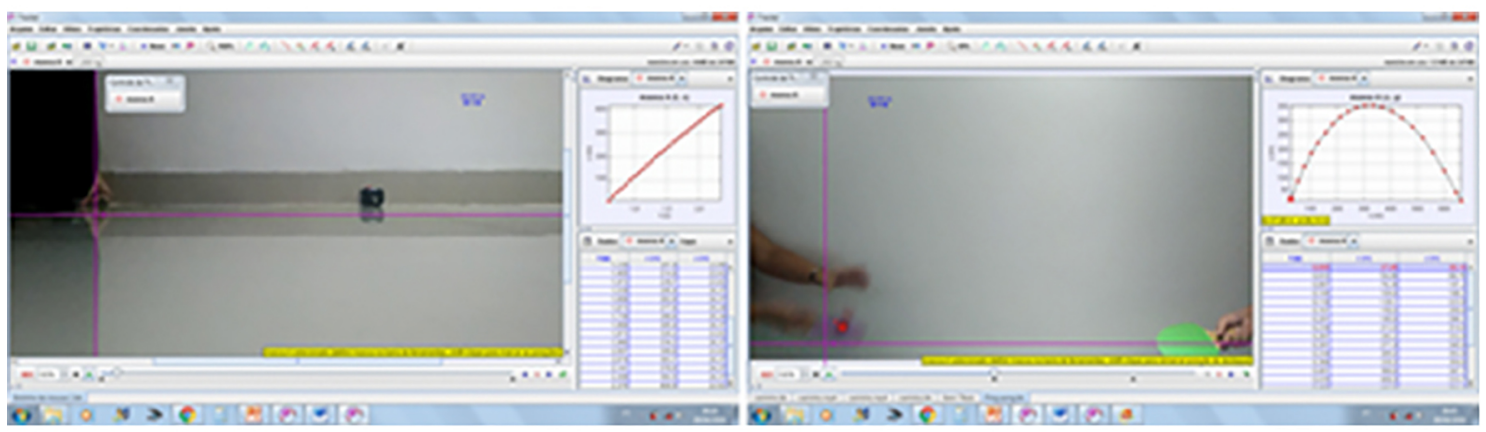

A videoanálise é realizada por um software livre relacionado a experimentos físicos chamado Tracker. O Tracker possibilita o mapeamento de movimentos quadro a quadro e o associa a construção de gráficos. O gráfico construído vai depender das variáveis associadas, como tempo e distância, tempo e altura alcançada, velocidade, aceleração entre outras. Responda as questões 8 e 9 com base nessas informações:

8) O pontos do gráfico associado à videoanálise do movimento da bola foi construído no plano cartesiano por meio de:
(A) quadrantes
(B) pares ordenados
(C) eixos cartesianos
(D) Nenhuma das respostas anteriores

9) Os movimentos tratados em videoanálise foram associados a gráficos. Esses gráficos correspondem à construção de funções por demonstrarem alguns aspectos, exceto em:

(A) correspondência biunívoca

(B) uma variável dependente de outra

(C) cada posição no eixo das abscissas tem um único correspondente no eixo das ordenadas

(D) cada posição no eixo das abscissas tem vários correspondentes no eixo das ordenadas 


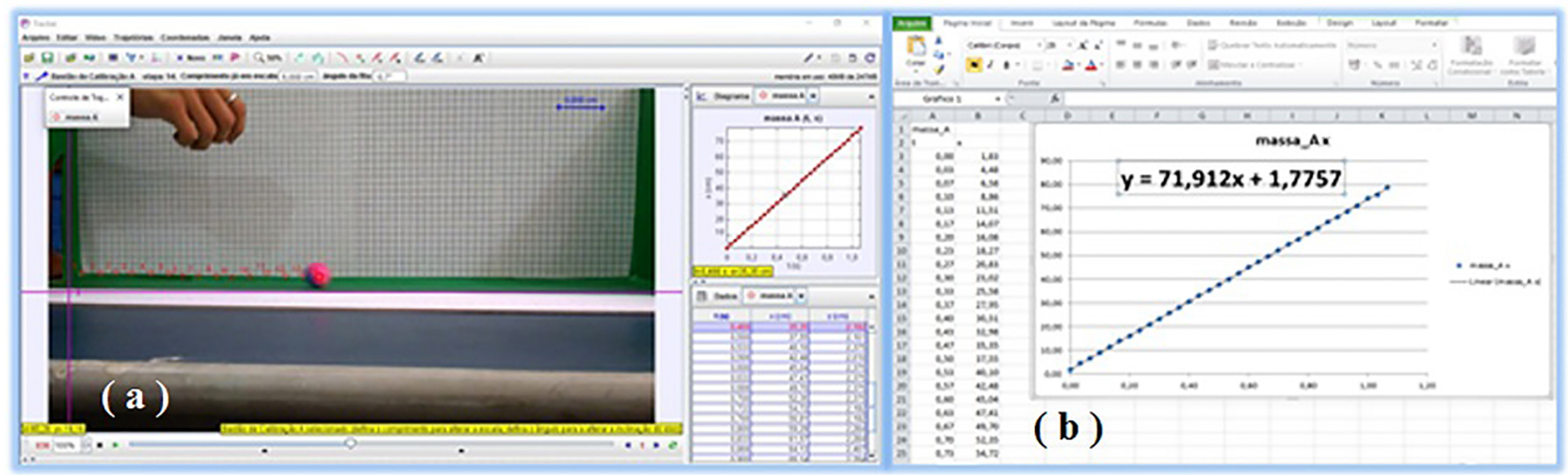

Figura 8: (a) Imagem de videoanálise de experimento de rolagem da bola de borracha, em MRU, promovido por aluno; (b) Imagem de gráfico de experimento de rolagem de bola de borracha em Excel. Fonte: Acervo pessoal

descendo a rampa, queda de bola com efeito de choque elástico.

A Figura 9(a) apresenta o print da videoanálise do experimento de simulação de jogo de ping pong e a Figura 9(b) apresenta o print do gráfico em Excel e respectiva lei de formação da função associada à videoanálise específica. Foram abordadas questões como regularidade, concavidade, lei de formação de funções quadráticas, coeficientes de funções, gráfico de uma função quadrática (parábola), máximo e mínimo de uma parábola, além do reforço de conceitos na construção de gráficos como eixos, pares ordenados e relação entre coordenadas cartesianas. O Quadro 4 apresenta algumas das questões tratadas nessa aula.

A sexta e última aula dupla da sequência didática também tratou de questionamentos pela metodologia IpC, com o uso dos cartões Plickers, envolvendo as videoanálises dos experimentos de cinemática da segunda e da quarta aula dupla, bem como debates que envolveram a definição das funções afim e quadrática ao longo do processo. A última etapa contou com a votação de 10 questões de múltipla escolha, onde recordaram funções afins e funções quadráticas, abordando, por meio da análise dos gráficos obtidos nas videoanálises, os movimentos, as leis de formação, coeficientes, concavidade, funções crescentes, decrescentes e constantes. O encerramento contou também com uma avaliação individual de cada aluno participante a cerca da sequência didática desenvolvida, com a explanação em linhas gerais da opinião de cada um deles em relação à experiência vivida.

\section{Resultados e Discussões}

As três turmas desenvolveram a proposta demonstrando interesse e curiosidade. De todos os pré-testes conceituais adotados no tratamento da sequência didática, alguns deles necessitaram de intervenção por discussão entre pares, sendo seguidos de pós-testes conceituais com textos distintos dos pré-testes. Enquanto se realizava a atividade os alunos pontuavam e comentavam cada etapa do experimento. Seus apontamentos geraram debates e seus registros tomaram forma de notas de aula a respeito do conceito aprendido envolvendo o Movimento Retilíneo Uniforme (MRU) e Uniformemente Variado (MUV), associados às construções respectivas de Funções Afins e Quadráticas. O dados, a serem capturados em função da resposta aos questionários por meio do Plickers na aplicação da metodologia IpC receberam análise estatística pelo método de "Ganho de Hake Normalizado".

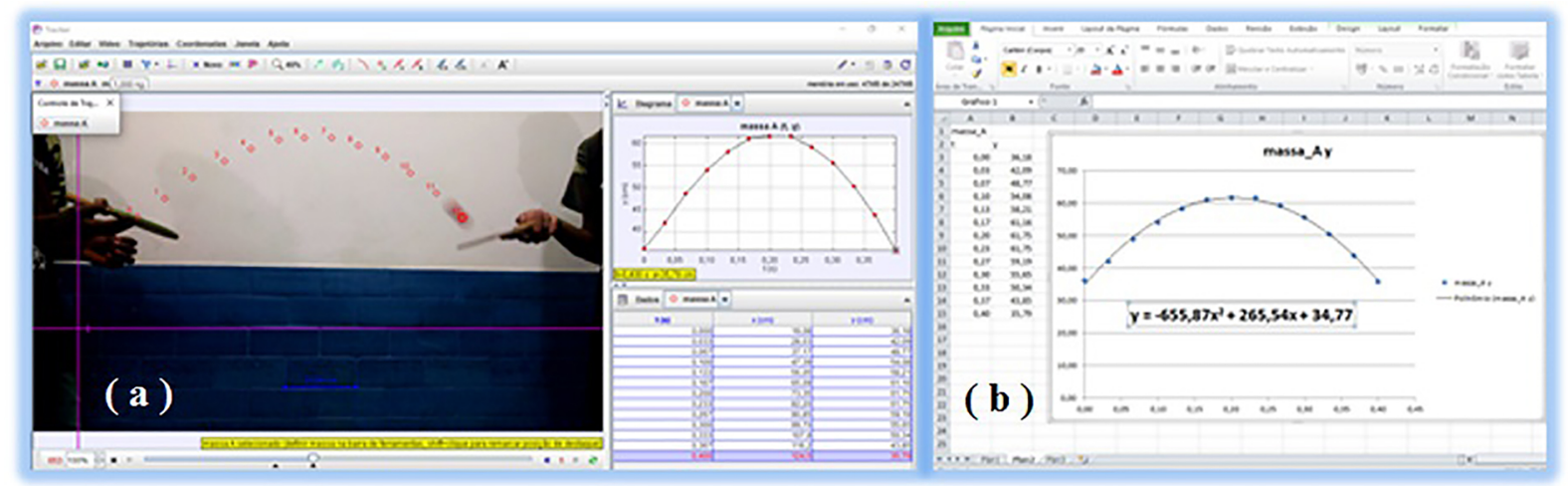

Figura 9: (a) Imagem de videoanálise de experimento de simulação jogo de ping pong promovido por alunos; (b) Imagem de gráfico de experimento da simulação de jogo de ping pong em Excel. Fonte: Acervo pessoal 
Quadro 3: Algumas questões aplicadas na aula de $\mathrm{IpC}$ destinada às funções afins

\begin{tabular}{|c|c|}
\hline $\begin{array}{l}\text { Q1 pré-teste) Quanto aos pontos marcados na trajetória da } \\
\text { bolinha de borracha pela videoanálise, podemos afirmar que: }\end{array}$ & $\begin{array}{l}\text { Q1 pós-teste) Quanto aos pontos marcados na trajetória do } \\
\text { carrinho pela videoanálise, podemos afirmar que: }\end{array}$ \\
\hline (A) Apresentam pouca linearidade no trajeto & (A) Apresentam pouca linearidade no trajeto \\
\hline (B) Apresentam linearidade no trajeto & (B) Apresentam linearidade no trajeto \\
\hline (C) Não apresentam linearidade & (C) Não apresentam linearidade \\
\hline (D) Nenhuma das respostas anteriores & (D) Nenhuma das respostas anteriores \\
\hline $\begin{array}{l}\text { Q2 pré-teste) Como ficou o gráfico montado com os pontos } \\
\text { da trajetória da bolinha que associa distância e tempo? }\end{array}$ & $\begin{array}{l}\text { Q2 pós-teste) Como ficou o gráfico montado com os pontos } \\
\text { da trajetória do carrinho que associa distância e tempo? }\end{array}$ \\
\hline (A) Se assemelha a uma reta crescente & (A) Se assemelha a uma reta decrescente \\
\hline (B) Se assemelha a uma reta constante & (B) Se assemelha a uma reta constante \\
\hline (C) Se assemelha a uma reta decrescente & (C) Se assemelha a uma reta crescente \\
\hline (D) Nenhuma das respostas anteriores & (D) Nenhuma das respostas anteriores \\
\hline $\begin{array}{l}\text { Q3 pré-teste) Em função do tempo decorrido, a distância } \\
\text { percorrida pela bolinha se mantém aparentemente proporci- } \\
\text { onal? }\end{array}$ & $\begin{array}{l}\text { Q3 pós-teste) Em função do tempo decorrido, a distância } \\
\text { percorrida pelo carrinho se mantém aparentemente proporci- } \\
\text { onal? }\end{array}$ \\
\hline (A) Sim (B) Em parte (C) Não & (A) Sim (B) Em parte (C) Não \\
\hline (D) Nenhuma das respostas anteriores & (D) Nenhuma das respostas anteriores \\
\hline $\begin{array}{l}\text { Q4 pré-teste) No instante inicial (tempo zero), o desloca- } \\
\text { mento (distância) de percurso da bolinha é: }\end{array}$ & $\begin{array}{l}\text { Q4 pós-teste) No instante inicial (tempo zero), o desloca- } \\
\text { mento (distância) de percurso do carrinho é: }\end{array}$ \\
\hline (A) Zero (B) Um (C) Impossível determinar & (A) Um (B) Zero (C) Impossível determinar \\
\hline (D) A bolinha chegou ao final do seu percurso & (D) O carrinho chegou ao final do seu percurso \\
\hline $\begin{array}{l}\text { Q5 pré-teste) Considerando a, b, c números reais, e a não } \\
\text { nulo, a lei de formação da função estabelecida pela trajetória } \\
\text { da bolinha se encaixa na definição: }\end{array}$ & $\begin{array}{l}\text { Q5 pós-teste) Considerando a, b, c números reais, e a não } \\
\text { nulo, a lei de formação da função estabelecida pela trajetória } \\
\text { do carrinho se encaixa na definição: }\end{array}$ \\
\hline (A) $y=a x^{2}+b x+c(B) y=a x(C) y=a x+b(D) y=b$ & (A) $y=a x^{2}+b x+c(B) y=a x+b(C) y=a x(D) y=b$ \\
\hline
\end{tabular}

Quadro 4: Algumas questões aplicadas na aula de IpC destinada às funções quadráticas

\begin{tabular}{|c|c|}
\hline $\begin{array}{l}\text { Q7 pré-teste) Sobre o experimento do percurso do car- } \\
\text { rinho na rampa, em movimento acelerado, podemos } \\
\text { afirmar que: }\end{array}$ & $\begin{array}{l}\text { Q7 pós-teste) Sobre o experimento da queda livre da } \\
\text { bolinha e seu retorno instantâneo, podemos afirmar } \\
\text { que: }\end{array}$ \\
\hline (A) O movimento é uniformemente variado & (A) O movimento não varia \\
\hline (B) O movimento é constante & (B) $\mathrm{O}$ movimento é constante \\
\hline (C) O movimento é retilíneo uniforme & (C) O movimento é uniformemente variado \\
\hline (D) Nenhuma das respostas anteriores & (D) Nenhuma das respostas anteriores \\
\hline $\begin{array}{l}\text { Q8 pré-teste) Sobre a função } \mathrm{y}=\mathrm{ax}^{2}+\mathrm{bx}+\mathrm{c} \text { asso- } \\
\text { ciada ao movimento da bola de ping pong, podemos } \\
\text { afirmar que: }\end{array}$ & $\begin{array}{l}\text { Q8 pós-teste) Sobre a função } \mathrm{y}=\mathrm{ax}^{2}+\mathrm{bx}+\mathrm{c} \text { asso- } \\
\text { ciada ao movimento da bola em queda livre e retorno } \\
\text { instantâneo, podemos afirmar: }\end{array}$ \\
\hline (A) $a>0$ (B) $a=0$ (C) $a<0$ (D) N.R.A & (A) $a>0$ (B) $a=0$ (C) $a<0$ (D) N.R.A. \\
\hline $\begin{array}{l}\text { Q9 pré-teste) Quanto ao coeficiente linear c da função } \\
\text { associada ao movimento da bolinha lançada no biboquê, } \\
\text { podemos dizer que é: }\end{array}$ & $\begin{array}{l}\text { Q9 pós-teste) Quanto ao coeficiente linear c da função } \\
\text { associada ao movimento da bolinha em queda livre, } \\
\text { podemos dizer que é: }\end{array}$ \\
\hline (A) Nulo (B) Não existe (C) Não nulo & (A) Nulo (B) Não existe \\
\hline (D) Não é possível determinar & (C) Não é possível determinar (D) Não nulo \\
\hline $\begin{array}{l}\text { Q10 pré-teste) Observando o gráfico associado ao expe- } \\
\text { rimento com a bola no jogo de pingpong ou no lança- } \\
\text { mento da bola no biboquê, podemos dizer que a única } \\
\text { resposta incorreta é: }\end{array}$ & $\begin{array}{l}\text { Q10 pós-teste) Observando o gráfico associado ao ex- } \\
\text { perimento com a bolinha de mouse descendo a rampa } \\
\text { ou no lançamento em queda livre da bolinha, podemos } \\
\text { dizer que a única resposta correta é: }\end{array}$ \\
\hline (A) A parábola está voltada para cima & (A) A parábola está voltada para baixo \\
\hline (B) A parábola está voltada para baixo & (B) A parábola está voltada para cima \\
\hline (C) A função tem ponto máximo & (C) A função tem ponto máximo \\
\hline (D) $\mathrm{O}$ coeficiente a é menor que zero & (D) O coeficiente a é menor que zero \\
\hline
\end{tabular}

O ganho de Hake normalizado é calculado pela razão descrita na equação 1 descrita abaixo e corresponde à melhora do escore do aluno em um teste padrão, que leva em consideração os resultados obtidos no pré-teste e pós-teste.

$$
g=\frac{\% \text { pós }-\% \text { pré }}{100 \%-\% \text { pre }}
$$

O numerador da equação está relacionado com o ganho efetivo obtido pelo aluno nos resultados do pré-teste e pós-teste, enquanto no denominador estará o desempenho máximo que poderá ser alcançado. Os valores estão entre
0 e 1 ( $0 \%$ e $100 \%)$, sendo que quanto maiores os valores, mais acentuado foi a melhora do desempenho do aluno.

Segundo Hake [12], podemos definir o ganho normalizado em três classes: considera-se ganho baixo os cálculos que apresentam valores de $\mathrm{g}<0,30$ (abaixo de $30 \%$ ); para ganho médio, considera-se os cálculos que apresentam valores dentro do intervalo $0,30<\mathrm{g}<0,70$ (entre $30 \%$ e $70 \%$ ); considera-se ganho alto os cálculos de g em que seus ganhos alcançam valores maiores que 0,70 (maior que $70 \%$ ); valores negativos correspondem a perdas e não a ganhos. 
O ganho normalizado também pode ser entendido como cálculo com os dados dos Testes Conceituais. Nesse caso, o numerador da equação será determinado pela diferença entre a porcentagem de acertos após e antes da discussão entre os colegas. $\mathrm{O}$ denominador corresponde, portanto, a máxima melhora na percentagem de acertos para a questão conceitual. De acordo com Mazur [7], turmas Peer Instruction (IpC) devem apresentar g >0,36, e o valor médio do ganho está entre $0,10<g<0,20$ para classes submetidas a métodos tradicionais. Os testes conceituais utilizados neste estudo, que entraram em discussão por pares, mostraram, em sua maioria, um ganho de Hake superior a 0,36. O Quadro 2 apresenta as questões onde a votação dos pré-testes se enquadrou entre $30 \%$ e $70 \%$ de acertos, distribuídas por turma participante. Nesses casos, segundo a metodologia IpC, é necessário nova breve explanação e votação de pós-testes conceituais. Os valores constantes do Quadro 5 para "g" foram retirados dos dados coletados nos 44 testes conceituais aplicados ao longo da sequencia didática.

Analisando os dados obtidos, de acordo com Mazur [7], verificamos que na turma 1 houve, na aplicação dos póstestes, ganho superior a 0,36 em 9 das 11 questões votadas após a discussão entre pares, correspondendo a $81 \%$ das votações, e em uma das questões não houve perda do ganho de Hake $(\mathrm{g}<0)$, correspondendo a $9 \%$. Já na turma 2, observamos uma perda em uma das aplicações de pós-testes e ganho superior a 0,36 em 9 das 12 questões votadas após discussão entre pares, correspondendo a $75 \%$ das votações. E na turma 3, apenas 2 questões entre as 13 votadas ficaram com ganho abaixo de 0,36 , correspondendo a $85 \%$ das votações com ganho superior a 0,36 .

Analisando os dados, de acordo com Hake [12], observamos na turma 1 que em uma questão houve ganho baixo ( $\mathrm{g}<0,3)$, em 4 questões houve ganho médio $(0,3<\mathrm{g}<0,7)$ e em 6 questões houve ganho alto $(g>0,7)$. Já na turma 2 , houve ganho baixo em uma questão, ganho médio em 3 questões e ganho alto em 7 questões. E na turma 3, apenas 2 questões apresentaram ganho baixo, 5 questões apresentaram ganho médio e 6 questões apresentaram ganho alto.

Fazendo um paralelo entre os dados obtidos pela Metodologia IpC com a análise de quase-experimentos de série temporal, apresentamos a seguir os quadros de análises dessas intervenções por turma e por dia letivo da sequência didática na qual a metodologia IpC foi implementada. Vamos considerar as videoanálises dos experimentos promovidos e filmados pelos alunos nas aulas duplas 2 e 4 da sequência didática como instrumento embasador para o tratamento entre pré-testes e pós-testes aplicados pela metodologia IpC. A discussão entre pares, indicada por Mazur [7] para votações no intervalo de acertos entre $30 \%$ e $70 \%$, será considerada como a intervenção de tratamento propriamente dita a ser analisada pelo delineamento quase-experimental.

O delineamento quase-experimental vai estudar o comportamento da aplicação da pesquisa e a variação de incidência de intervenções (discussão entre pares). Dessa forma, os quadros que seguem vão indicar essa incidência em cada turma participante, distribuídas nas votações realizadas nas aulas duplas 1, 3, 5 e 6 da sequência didática, a fim de comparar a evolução dessas votações mediante o tratamento, bem como diagnosticar possível contribuição da videoanálise na redução do tratamento em virtude do aumento de significância e entendimento de conceitos por parte dos alunos envolvidos, contribuindo para melhora percentual ou não nas votações de pré-testes.

A discussão entre pares, além da contribuição da videoanálise, é analisada à luz do delineamento quaseexperimental com relação ao seu efeito em aumento ou não do percentual de votações dos pós-testes em relação aos pré-testes conceituais associados.

Na sequência didática estudada temos a metodologia IpC associada a intervenções por videoanálise de experimentos. O efeito é o percentual de acertos em votações de pré e pós-testes. A causa é a videoanálise de experimentos embasando questionamentos para votações em pré-testes conceituais e os pós-testes posteriores à discussão entre pares. A videoanálise de experimentos entra como variável independente (VI) e as votações de pré e pós-testes

Quadro 5: Cálculos de Ganho de Hake Normalizado

\begin{tabular}{|c|c|c|c|c|c|c|c|c|}
\hline TURMA 1 & & & TURMA & & & TURMA 3 & & \\
\hline Q10 & QUESTÃO & $\begin{array}{l}\text { GANHO } \\
\text { HAKE }\end{array}$ & $\overline{A U L A}$ & QUESTÃO & $\begin{array}{l}\text { GANHO } \\
\text { HAKE }\end{array}$ & AULA & QUESTÃO & $\begin{array}{l}\text { GANHO } \\
\text { HAKE }\end{array}$ \\
\hline \multirow[t]{3}{*}{ Aula 1 IpC } & Q2 & 1 & \multirow{6}{*}{ Aula $1 \mathrm{IpC}$} & Q1 & 1 & & Q1 & 0,45 \\
\hline & Q14 & 0,3 & & Q4 & 1 & Aula 1 IpC & Q4 & 0,43 \\
\hline & Q1 & 0,86 & & Q5 & 0,8 & & Q7 & 0,13 \\
\hline \multirow[t]{3}{*}{ Aula 2IpC } & Q5 & 0,79 & & Q7 & 0,29 & & Q8 & 0,14 \\
\hline & Q7 & 0,5 & & Q8 & 0,86 & & Q10 & 1 \\
\hline & Q8 & 0,64 & & Q10 & 0,9 & & Q12 & 1 \\
\hline \multirow[t]{2}{*}{ Aula $3 \mathrm{IpC}$} & Q6 & 0,45 & \multirow[t]{2}{*}{ Aula 2 IpC } & Q3 & 0,33 & & Q14 & 0,64 \\
\hline & Q7 & 0,75 & & Q7 & 0,71 & Aula 2 IpC & Q2 & 0,71 \\
\hline \multirow[t]{5}{*}{ Aula 4 IpC } & Q3 & 0,22 & \multirow{3}{*}{ Aula IpC 3} & Q9 & 0,3 & & Q6 & 0,77 \\
\hline & Q7 & $-0,9$ & & Q6 & 0,57 & Aula 3 IpC & Q1 & 1 \\
\hline & Q8 & 0,83 & & & & & Q8 & 0,75 \\
\hline & & & \multirow{2}{*}{ Aula 4 IpC } & Q3 & 1 & Aula 4 IpC & Q3 & 0,6 \\
\hline & & & & Q8 & 0,81 & & Q8 & 0,6 \\
\hline
\end{tabular}


conceituais entram como as variáveis dependentes (VD) da presente pesquisa.

A lógica dos quase-experimentos está em não realizar a distribuição aleatória das unidades nas condições, porém possuir os mesmos propósitos e atributos estruturais dos experimentos. No experimento puro as explicações alternativas tornam-se pouco plausíveis porque o delineamento assegura que essas explicações alternativas estejam distribuídas aleatoriamente nas condições. No quase experimento, como não é feita distribuição aleatória de unidades nas condições, são usados outros princípios para mostrar que explicações alternativas não são plausíveis. Esse desenho tem mérito quando existem conhecimentos específicos sobre como a variável dependente se comporta (ou vem se comportando). A ausência de um grupo controle dificulta o diagnóstico se o efeito ocorreria ou não sem o tratamento, mas a questão ética é preservada, uma vez que, no nosso entendimento, todas as turmas de alunos envolvidos no processo investigado, deveriam ser contempladas com a experiência da videoanálise.

Para que as inferências sejam válidas sobre o efeito do tratamento (percentual de acertos), é preciso que o efeito seja significativo sobre a VD. O objetivo é mostrar que os resultados aumentam na presença e diminuem na ausência de um dado tratamento. O relacionamento entre alunos e a discussão entre pares, em mesma linguagem, propiciando votações de pós-testes, entram como explicações alternativas onde cada medida pós-teste refere-se a um construto diferente que será comparado aos padrões de efeitos (percentual de acertos nas votações) geradas por diferentes causas possíveis (videoanálises).

O tratamento identificado como a intervenção por discussão entre pares, precedendo a votação de pós-testes (OTP), onde o tratamento (I) é introduzido de acordo com os resultados (OT) apresentados, entendemos que as aplicações do tratamento vão evoluir enquanto diminuírem suas incidências, indicando que a instrução pelos colegas, associadas ao entendimento das videoanálises abordadas, podem contribuir para um melhor entendimento de conceitos. A análise da sequência do tratamento indica o comportamento da pesquisa.

Os Quadros 6, 7, 8 e 9 demonstram as séries temporais analisadas na turma 1 , respectivamente associados à primeira, segunda, terceira e quarta aula de aplicação do IpC. Na aula de introdução, onde foram tratadas questões prévias, foram necessárias 2 intervenções das 14 abordadas, enquanto que na segunda aula, baseada na videoanálise de experimentos associados às funções afins, já foram necessárias 4 intervenções entre as 10 abordadas. Com relação às questões da terceira aula de aplicação da metodologia IpC, baseadas na videoanálise de experimentos associados às funções quadráticas, apenas duas intervenções foram necessárias, onde a turma demonstrou facilidade em responder a maioria das questões abordadas. A quarta aula de aplicação da metodologia IpC e sexta da sequência didática, trouxe 3 intervenções das 10 abordadas.
A Figura 10 apresenta o gráfico comparativo das votações de pré-testes e pós-testes onde ocorreram as intervenções. Em 11 das 44 votações em pré-testes ocorreram intervenções de discussão entre pares e votações de póstestes, totalizando $25 \%$. Em 10 intervenções o percentual das votações dos pós-testes superou o percentual dos pré-testes. Em um deles (Q5 da sexta aula dupla) o percentual de votação do pós-teste foi menor do que na votação do pré-teste.

Os Quadros 10, 11, 12 e 13 demonstram as séries temporais analisadas na turma 2 , respectivamente associados à primeira, segunda, terceira e quarta aula de aplicação do IpC. Na aula de introdução, diferente da primeira turma, foram necessárias 6 intervenções das 14 abordadas, enquanto que na segunda aula foram necessárias apenas 3 intervenções entre as 10 abordadas. A turma também demonstrou facilidade em responder a maioria das questões abordadas na terceira aula de aplicação da metodologia IpC, onde houve apenas uma intervenção. A quarta aula de aplicação do IpC trouxe 2 intervenções das 10 abordadas.

A Figura 11 apresenta o gráfico comparativo das votações de pré-testes e pós-testes onde ocorreram as intervenções. Em 12 das 44 votações em pré-testes ocorreram intervenções de discussão entre pares e votações de póstestes, alcançando $27 \%$ do total de votações. Em 12

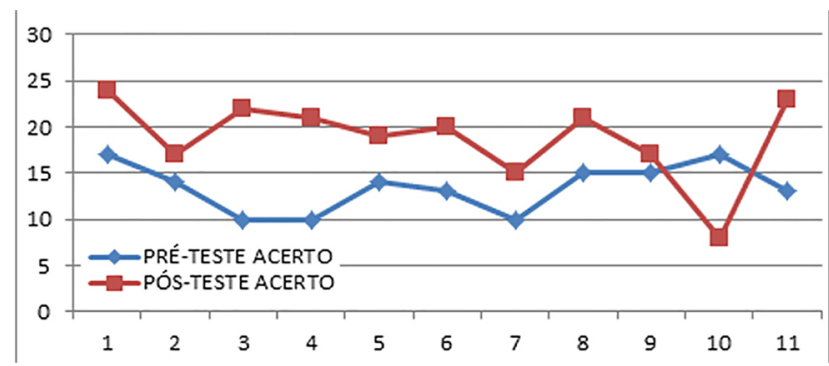

Figura 10: Turma 1 - Gráfico comparativo das questões com incidência de pós-testes Legenda: Eixo vertical: quantidade de acertos em votações; Eixo horizontal: observações de votações OTPs (incidência de pós-testes) de série temporal constantes, respectivamente, dos Quadros 3 a 6.

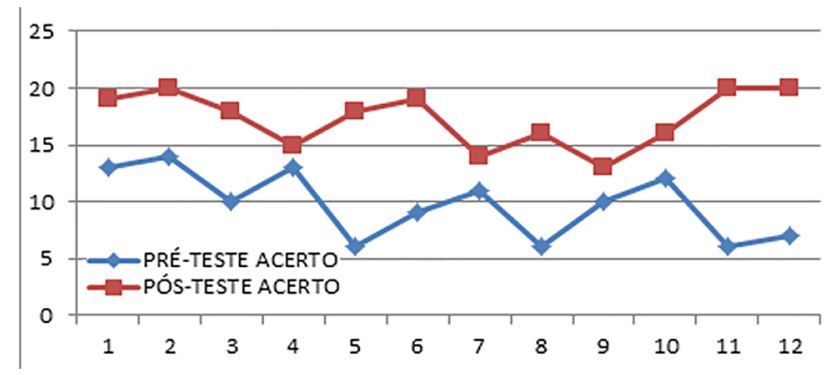

Figura 11: Turma 2 - Gráfico comparativo das questões com incidência de pós-testes Legenda: Eixo vertical: quantidade de acertos em votações; Eixo horizontal: observações de votações OTPs (incidência de pós-testes) de série temporal constantes, respectivamente, dos Quadros 7 a 10. 
Quadro 6: Turma 1 - Análise de Quase-experimentos em série temporal - Introdução $\mathrm{OT}_{1} \mathrm{OT}_{2} \mathbf{I} \mathbf{O T P}_{\mathbf{2}} \mathrm{OT}_{3} \mathrm{OT}_{4} \mathrm{OT}_{5} \mathrm{OT}_{6} \mathrm{OT}_{7} \mathrm{OT}_{8} \mathrm{OT}_{9} \mathrm{OT}_{10} \mathrm{OT}_{11} \mathrm{OT}_{12} \mathrm{OT}_{13} \mathrm{OT}_{14} \mathbf{I}_{\mathbf{O}} \mathbf{O T P}_{\mathbf{1 4}}$

Legenda: $\mathrm{O}$ - observação de votações; $\mathrm{T}_{\alpha}$ - pré-testes conceituais; $\mathrm{TP}_{\alpha}$ - pós-testes conceituais; I - intervenções (discussão entre pares); $\propto \in Z / 1 \leq \propto \leq 14$

Quadro 7: Turma 1 - Análise de Quase-experimentos em série temporal - Funções Afins

$\mathrm{OT}_{1} \mathbf{I}_{\mathbf{O T P}} \mathbf{O T T}_{\mathbf{1}} \mathrm{OT}_{2} \mathrm{OT}_{3} \mathrm{OT}_{4} \mathrm{OT}_{5} \mathbf{I}_{\mathbf{O T P}_{\mathbf{5}}} \mathrm{OT}_{6} \mathrm{OT}_{\mathbf{7}} \mathbf{I} \mathbf{O T P}_{\mathbf{7}} \mathrm{OT}_{8} \mathbf{I} \mathbf{O T P}_{\mathbf{8}} \mathrm{OT}_{9} \mathrm{OT}_{10}$

Legenda: $\mathrm{O}$ - observação de votações; $\mathrm{T}_{\alpha}$ - pré-testes conceituais; $\mathrm{TP}_{\alpha}$ - pós-testes conceituais; I - intervenções (discussão entre pares); $\propto \in Z / 1 \leq \propto \leq 10$

Quadro 8: Turma 1 - Análise de Quase-experimentos em série temporal - Funções Quadráticas $\mathrm{OT}_{1} \mathrm{OT}_{2} \mathrm{OT}_{3} \mathrm{OT}_{4} \mathrm{OT}_{5} \mathrm{OT}_{6} \mathbf{I} \mathbf{O T P}_{6} \mathrm{OT}_{7} \mathbf{I}_{\mathbf{O}} \mathbf{O T P}_{\mathbf{7}} \mathrm{OT}_{8} \mathrm{OT}_{9} \mathrm{OT}_{10}$

Legenda: $\mathrm{O}$ - observação de votações; $\mathrm{T}_{\alpha}$ - pré-testes conceituais; $\mathrm{TP}_{\alpha}$ - pós-testes conceituais; I - intervenções (discussão entre pares); $\propto \in Z / 1 \leq \propto \leq 10$

Quadro 9: Turma 1 - Análise de Quase-experimentos em série temporal - Conclusão $\mathrm{OT}_{1} \mathrm{OT}_{2} \mathrm{OT}_{3} \mathbf{I}_{\mathbf{O T P}} \mathbf{O T T}_{4} \mathrm{OT}_{4} \mathrm{OT}_{5} \mathrm{OT}_{6} \mathrm{OT}_{7} \mathbf{I}_{\mathbf{O T P}} \mathbf{O T}_{\mathbf{7}} \mathrm{OT}_{8} \mathbf{I}_{\mathbf{O T}} \mathbf{O T}_{\mathbf{8}} \mathrm{OT}_{9} \mathrm{OT}_{10}$

Legenda: $\mathrm{O}$ - observação de votações; $\mathrm{T}_{\alpha}$ - pré-testes conceituais; $\mathrm{TP}_{\alpha}$ - pós-testes conceituais; I - intervenções (discussão entre pares); $\propto \in Z / 1 \leq \propto \leq 10$

Quadro 10: Turma 2 - Análise de Quase-experimentos em série temporal - Introdução

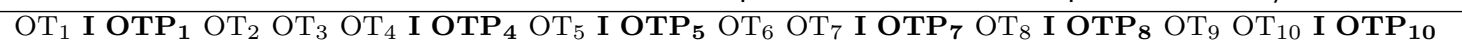
$\mathrm{OT}_{11} \mathrm{OT}_{12} \mathrm{OT}_{13} \mathrm{OT}_{14}$

Legenda: $\mathrm{O}$ - observação de votações; $\mathrm{T}_{\alpha}$ - pré-testes conceituais; $\mathrm{TP}_{\alpha}$ - pós-testes conceituais; I - intervenções (discussão entre pares); $\propto \in Z / 1 \leq \propto<14$

Quadro 11: Turma 2 - Análise de Quase-experimentos em série temporal - Funções Afins $\mathrm{OT}_{1} \mathrm{OT}_{2} \mathrm{OT}_{3} \mathbf{I} \mathbf{O T P}_{\mathbf{1}} \mathrm{OT}_{4} \mathrm{OT}_{5} \mathrm{OT}_{6} \mathrm{OT}_{7} \mathbf{I} \mathbf{O T P}_{\mathbf{7}} \mathrm{OT}_{8} \mathrm{OT}_{9} \mathbf{I} \mathbf{O T P}_{\mathbf{8}} \mathrm{OT}_{10}$

Legenda: $\mathrm{O}$ - observação de votações; $\mathrm{T}_{\alpha}$ - pré-testes conceituais; $\mathrm{TP}_{\alpha}$ - pós-testes conceituais; I - intervenções (discussão entre pares); $\propto \in Z / 1 \leq \propto \leq 10$

Quadro 12: Turma 2 - Análise de Quase-experimentos em série temporal - Funções Quadráticas $\mathrm{OT}_{1} \mathrm{OT}_{2} \mathrm{OT}_{3} \mathrm{OT}_{4} \mathrm{OT}_{5} \mathrm{OT}_{6} \mathbf{I} \mathbf{O T P}_{6} \mathrm{OT}_{7} \mathrm{OT}_{8} \mathrm{OT}_{9} \mathrm{OT}_{10}$

Legenda: $\mathrm{O}$ - observação de votações; $\mathrm{T}_{\alpha}$ - pré-testes conceituais; $\mathrm{TP}_{\alpha}$ - pós-testes conceituais; I - intervenções (discussão entre pares); $\propto \in Z / 1 \leq \propto \leq 10$

Quadro 13: Turma 2 - Análise de Quase-experimentos em série temporal - Conclusão

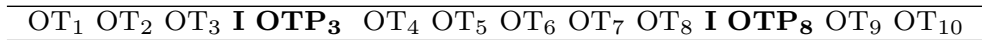

Legenda: $\mathrm{O}$ - observação de votações; $\mathrm{T}_{\alpha}$ - pré-testes conceituais; $\mathrm{TP}_{\alpha}$ - pós-testes conceituais; I - intervenções (discussão entre pares); $\propto \in Z / 1 \leq \propto \leq 10$

intervenções o percentual das votações dos pós-testes superou o percentual dos pré-testes. Em apenas um deles (Q1 da sexta aula dupla) o percentual de votação do pós-teste foi menor do que na votação do pré-teste.

Os Quadros 14, 15, 16 e 17 demonstram as séries temporais analisadas na turma 3 , respectivamente associados à primeira, segunda, terceira e quarta aula de aplicação do IpC. Na aula de introdução, semelhante à segunda turma, foram necessárias 7 intervenções das 14 abordadas, enquanto que na segunda aula foram necessárias apenas 2 intervenções entre as 10 abordadas. A turma também demonstrou facilidade em responder a maioria das questões abordadas na terceira aula de aplicação da metodologia IpC, onde houve apenas 2 intervenções.

A quarta aula de aplicação da metodologia IpC trouxe, igualmente à segunda turma, 3 intervenções das 12 abordadas. A Figura 12 apresenta o gráfico comparativo das votações de pré-testes e pós-testes onde ocorreram as intervenções. Em 13 das 44 votações em pré-testes ocorreram intervenções de discussão entre pares e votações de pós-testes, aproximando-se de 30\%. Em todas as intervenções o percentual das votações dos pós-testes superou o percentual dos pré-testes.

De acordo com Dutra e Reis [13], o desenho de série de tempo interrompida envolve um único grupo. Nesse caso, o fenômeno de interesse é medido ao longo do tempo e em algum momento é inserida a intervenção. O uso de um período amplo para coleta de dados visa minimizar ameaças à validade dos dados e efeitos de história (tendência temporal).

Na pesquisa em questão, o grupo analisado, distribuído em três turmas, recebeu o mesmo tratamento e as intervenções, isto é, as interrupções realizadas nas turmas pelos pós-testes, em virtude do diagnóstico fornecido nas votações por meio do plickers.com que atendiam ao in- 
Quadro 14: Turma 3 - Análise de Quase-experimentos em série temporal - Introdução

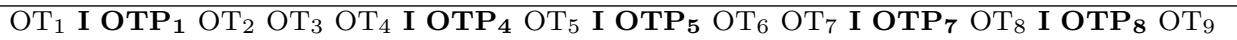
$\mathrm{OT}_{10} \mathbf{I}_{\mathbf{O T P}} \mathbf{O T}_{10} \mathrm{OT}_{11} \mathrm{OT}_{12} \mathbf{I}_{\mathbf{O T P}} \mathbf{O T}_{\mathbf{1 2}} \mathrm{OT}_{13} \mathrm{OT}_{14} \mathbf{I}_{\mathbf{O T P}} \mathbf{O T}_{\mathbf{1 4}}$

Legenda: $\mathrm{O}$ - observação de votações; $\mathrm{T}_{\alpha}$ - pré-testes conceituais; $\mathrm{TP}_{\alpha}$ - pós-testes conceituais; I - intervenções (discussão entre pares); $\propto \in Z / 1 \leq \propto \leq 14$

Quadro 15: Turma 3 - Análise de Quase-experimentos em série temporal - Funções Afins $\begin{array}{lllllllll}\mathrm{OT}_{1} & \mathrm{OT}_{2} \mathbf{I} & \mathbf{O T P} \\ \mathbf{2} & \mathrm{OT}_{3} & \mathrm{OT}_{4} & \mathrm{OT}_{5} & \mathrm{OT}_{6} \mathbf{I} \mathbf{O T P}_{6} & \mathrm{OT}_{7} & \mathrm{OT}_{8} & \mathrm{OT}_{9} & \mathrm{OT}_{10}\end{array}$

Legenda: $\mathrm{O}$ - observação de votações; $\mathrm{T}_{\alpha}$ - pré-testes conceituais; $\mathrm{TP}_{\alpha}$ - pós-testes conceituais; I - intervenções (discussão entre pares); $\propto \in Z / 1 \leq \propto \leq 10$

Quadro 16: Turma 3 - Análise de Quase-experimentos em série temporal - Funções Quadráticas $\mathrm{OT}_{1} \mathbf{I} \mathbf{O T P}_{\mathbf{1}} \mathrm{OT}_{2} \mathrm{OT}_{3} \mathrm{OT}_{4} \mathrm{OT}_{5} \mathrm{OT}_{6} \mathrm{OT}_{7} \mathrm{OT}_{8} \mathbf{I} \mathbf{O T P}_{8} \mathrm{OT}_{9} \mathrm{OT}_{10}$

Legenda: $\mathrm{O}$ - observação de votações; $\mathrm{T}_{\alpha}$ - pré-testes conceituais; $\mathrm{TP}_{\alpha}$ - pós-testes conceituais; $\mathrm{I}$ - intervenções (discussão entre pares); $\propto \in Z / 1 \leq \propto \leq 10$

Quadro 17: Turma 3 - Análise de Quase-experimentos em série temporal - Conclusão

$\begin{array}{lllllllllll}\mathrm{OT}_{1} \mathbf{I} \mathbf{O T P}_{\mathbf{1}} & \mathrm{OT}_{2} & \mathrm{OT}_{3} \mathbf{I} \mathbf{O T P}_{\mathbf{3}} & \mathrm{OT}_{4} & \mathrm{OT}_{5} & \mathrm{OT}_{6} & \mathrm{OT}_{7} & \mathrm{OT}_{8} & \mathrm{OT}_{9} \mathbf{I} \mathbf{O T P}_{\mathbf{9}} \mathrm{OT}_{10} & \mathrm{OT}_{11} & \mathrm{OT}_{12}\end{array}$

Legenda: $\mathrm{O}$ - observação de votações; $\mathrm{T}_{\alpha}$ - pré-testes conceituais; $\mathrm{TP}_{\alpha}$ - pós-testes conceituais; I - intervenções (discussão entre pares); $\propto \in Z / 1 \leq \propto \leq 10$

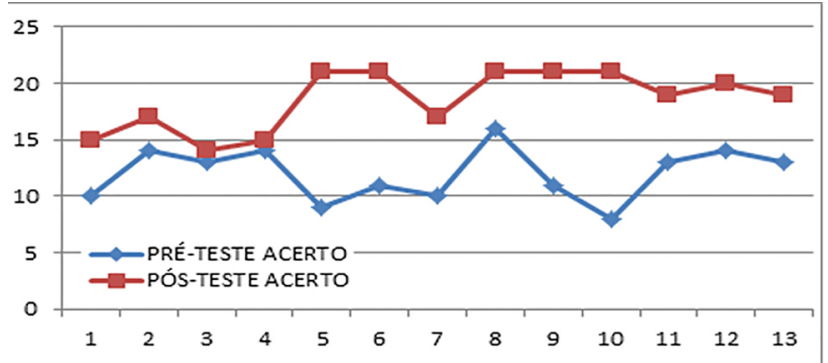

Figura 12: Turma 3 - Gráfico comparativo das questões com incidência de pós-testes Legenda: Eixo vertical: quantidade de acertos em votações; Eixo horizontal: observações de votações OTPs (incidência de pós-testes) de série temporal constantes, respectivamente, dos Quadros 11 a 14.

tervalo de $30 \%$ a $70 \%$ de acertos, desenharam a série temporal de cada turma ao longo da sequência didática.

Observamos em algumas questões, onde a discussão pelos pares e votações pós-testes ocorreram, percentuais baixos de ganho de Hake, mantendo a faixa entre 30 e $70 \%$, indicando que as incertezas permaneciam por parte dos alunos. Cabe citar a questão Q7 da última aula de aplicação da metodologia IpC, em aplicação na turma 1, onde foi diagnosticado perda no ganho de Hake no tratamento. A questão Q7 tratou da definição e diferenças entre funções crescentes, decrescentes e constantes, a partir da lei de formação de função obtida por meio de uma videoanálise de experimento, e a turma 1 não apresentou melhora no percentual entre as votações de pré e pós-testes, ao contrário, demonstrou confusão no entendimento, implicando no resultado. Entendemos que, nesse caso, houve desvio no método IpC e o objetivo não foi alcançado. Para reduzir desvios como esses, questões mais aprofundadas com atividades numéricas e apoio de livro didático, adotado para o ano letivo em que a pesquisa foi aplicada [14], foram utilizados nos dias letivos subsequentes à aplicação da sequência didática de forma a aprofundar os conceitos construídos por meio da sequência aplicada, visando sanar dificuldades apresentadas como nesta questão.

A presente pesquisa introduz o tema, mas não se debruça em exercícios numéricos. O objetivo se limita ao entendimento para construção do conceito de funções. As turmas participantes do projeto tiveram acesso a exercícios extras após a sequência didática apresentada aqui.

Vale lembrar que a diversidade em sala de aula possibilita muitas respostas e situações distintas. Há alunos que, mesmo diante de situações diferenciadas em sala de aula, insistem em não se envolverem ou não se interessarem. A impressão que tivemos ao longo da aplicação da sequência didática é de que esse problema foi minimizado ao passo que todos os participantes precisavam estar atentos aos questionamentos, pois os mesmos precisavam votar em tempo real, diferente de aulas expositivas, onde muitas vezes alunos apresentam desinteresse e total ausência em participação. A votação em tempo real chamava a todos para a participação, incluindo mesmo aqueles insistentes na ausência.

A abordagem experimental associada à prática de metodologia ativa trouxe para o aluno uma nova visão, por levá-lo a entender a sala de aula de uma outra forma, abrindo caminho para outras possibilidades. Cabe ao docente lidar com as negativas e afirmativas da mesma forma, pois ambas vão contribuir para reflexão e melhora da prática, sendo de grande importância identificar o posicionamento dos alunos diante de uma realidade que faz parte do seu cotidiano. Entendemos, dessa forma, que a presente pesquisa trouxe muitas ideias para estudos e 
aplicações futuras, na busca de inovação e melhora na qualidade de ensino.

\section{Considerações Finais}

A vivência em sala de aula, por meio de uma aprendizagem partindo do concreto, proporcionou ao aluno a possibilidade de interação, diálogo e debate de conceitos, onde o estudo das funções foi oferecido com associação a experiências da rotina do aluno.

Dos objetivos traçados para a aplicação do presente estudo, entendemos que obtivemos bons resultados no alcance de quase todos, uma vez que a resposta na aplicação da proposta foi positiva em sua maioria, conforme analisado no capítulo anterior. O objetivo geral visava investigar como a Metodologia Ativa IpC, associada à videoanálise de experimentos de cinémática, pode contribuir para a aprendizagem do corpo discente a cerca de funções. Conforme analisado, as turmas participantes apresentaram melhores resultados na maioria das intervenções de discussão entre pares, com percentual de votação superior em pós-testes em comparação aos pré-testes. Por outro lado, a evolução das aulas pertencentes à sequência didática apresentaram uma necessidade menor de intervenções após as aulas de experimentações.

Entendemos que lidar com o concreto, associar à construção de gráficos por meio do conhecimento da videoanálise, proporcionou um melhor entendimento e mais facilidade de associações para a construção dos conceitos constantes dos objetivos específicos por parte do corpo discente participante da amostra de estudo. Atendemos à abordagem de questões do cotidiano relacionando Matemática e Física por meio da experimentação, além da construção do conceito de funções afins e quadráticas e associações aos respectivos gráficos, abordadas por meio da videoanálise, bem como as análises estatísticas dos resultados computados.

Acreditamos na eficácia da proposta e entendemos que a mesma sempre pode ser flexibilizada no seu tempo de aplicação, dependendo do foco e da área afim a qual será aplicada, bem como a lógica de abordagem de modo a adaptar a cada público participante, adequando-se aos perfis do docente e do corpo discente envolvido.

\section{Agradecimentos}

Os autores agradecem à colaboração do Professor $\mathrm{PhD}$. Vitor Luiz Bastos de Jesus para a realização deste trabalho.

\section{Referências}

[1] MINISTÉRIO DA EDUCAÇÃO, Base Nacional Comum Curricular, 19 de dezembro de 2018. Brasília, 2018. Disponível em: http://basenacionalcomum.mec.gov.br/ images/BNCC_E_EF_110518_versaofina_site.pdf
[2] MINISTÉRIO DA EDUCAÇÃO, Guia de livros didáticos: PNLD 2011: Matemática (Ministério da Educação, Brasília, 2010).

[3] MINISTÉRIO DA EDUCAÇÃO, Guia de livros didáticos: PNLD 2012: Matemática (Ministério da Educação, Brasília, 2011).

[4] D.T. Campbell e J.C. Stanley, Experimental and quaseexperimental designs for research (Houghton Mifflin Company, Boston, 1963).

[5] P.C. Cozby, Métodos de Pesquisa em Ciencias do comportamento (Editora Atlas, São Paulo, 2003).

[6] A.S.S. Pinto, M.R.P. Bueno, M.A.F.A. Silva, M.Z. Sellman e S.M.F. Koehler, Janus 9, 75 (2012).

[7] E. Mazur, Peer Instruction: A revolução da aprendizagem ativa (Penso, Porto Alegre, 2015).

[8] I.S. Araujo e E. Mazur, Caderno Brasileiro de Ensino de Física 30, 362 (2013).

[9] V.L.B. de Jesus, Experimentos e Vídeo análise - Dinâmica (Livraria da Física, São Paulo, 2014).

[10] D. Brown e A.J. Cox, The Physics Teacher 47, 145 (2009).

[11] A.G. Bezerra Júnior, J.A. Lenz, L.P. Oliveira e N. Saavedra, Manual para Usuários Iniciantes no Software Tracker (Universidade Tecnológica Federal do Paraná, Curitiba, 2011).

[12] R.R. Hake, American Journal of Physics 66, 64 (1998).

[13] H.S. Dutra e V.N. Reis, Revista de Enfermagem UFPE on line 10, 2230 (2016).

[14] E. Silveira, Matemática Compreensão e Prática- $9^{\circ}$ Ano (Editora Moderna, São Paulo, 2015), $3^{\text {a }}$ ed. 